Article

\title{
Removal of Chloramphenicol from Aqueous Solution Using Low-Cost Activated Carbon Prepared from Typha orientalis
}

\author{
Yiran Li, Jian Zhang * and Hai Liu \\ School of Environmental Science and Engineering, Shandong University, Jinan 250100, China; \\ liyr1987@foxmail.com (Y.L.); hunanliuhai@gmail.com (H.L.) \\ * Correspondence: zhangjian00@sdu.edu.cn; Tel.: +86-531-8836-1185
}

Received: 18 February 2018; Accepted: 19 March 2018; Published: 22 March 2018

\begin{abstract}
Low-cost and efficient activated carbon (AC) was prepared from Typha orientalis via phosphoric acid activation for chloramphenicol (CAP) removal. The adsorption capacity and mechanisms of CAP on AC were investigated. The physicochemical properties of AC were characterized by an $\mathrm{N}_{2}$ adsorption/desorption isotherm, elemental analysis, Boehm's titration and X-ray photoelectron spectroscopy (XPS). The effects of experimental parameters were investigated to study the adsorption behaviors of CAP on AC, including contact time, initial concentration, ionic strength, and initial $\mathrm{pH}$. AC had a micro-mesoporous structure with a relatively large surface area $\left(794.8 \mathrm{~m}^{2} / \mathrm{g}\right)$. The respective contents of acidic and basic functional groups on AC were 2.078 and $0.995 \mathrm{mmol} / \mathrm{g}$. The adsorption kinetic that was well described by a pseudo-second-order rate model implied a chemical controlling step. The adsorption isotherm was well fitted with the Freundlich isotherm model, and the maximum CAP adsorption capacity was $0.424 \mathrm{mmol} / \mathrm{g}$. The ionic strength and $\mathrm{pH}$ had minimal effects on CAP adsorption. The dominant CAP adsorption mechanisms on AC were evaluated and attributed to $\pi-\pi$ electron-donor-acceptor (EDA) interaction, hydrophobic interaction, in conjunction with hydrogen-bonding interaction. Additionally, AC exhibited an efficient adsorption performance of CAP in a realistic water environment.
\end{abstract}

Keywords: activated carbon; adsorption; chloramphenicol; mechanism; antibiotic

\section{Introduction}

Chloramphenicol (CAP) as a broad-spectrum antibiotic is commonly used as a human antibiotic and veterinary drug due to its low cost and excellent antibacterial effects against many Gram-positive and Gram-negative bacteria [1,2]. However, CAP has many dangerous side-effects, including aplastic anaemia, genotoxic carcinogenicity and gray baby syndrome [3-5]. In addition, antibiotic resistance is another risk of indiscriminate use of $\mathrm{CAP}$, which makes the diseases caused by microorganisms difficult or impossible to be cured [6]. To reduce the threat to public health from CAP residues, a minimum required performance limit (MRPL) of $0.3 \mu \mathrm{g} / \mathrm{kg}$ for CAP in products of animal origin has been set by the European Union [7]. Although CAP is banned for use in food production in many countries, including the European Union, United States, Canada, Australia, Japan, and China $[1,8]$, the wastewater from antibiotic manufacturing, improper disposals of drugs or illegal usage in aquaculture still pollutes the water environment $[8,9]$. CAP can be detected frequently in surface water, groundwater, wastewater and even drinking water [10]. Therefore, it is necessary and important to develop a sensitive and cost-effective strategy for extraction of CAP in contaminated waters. Until now, only a few studies on CAP removal from water or wastewater have been reported, especially using porous carbon materials such as low-cost activated carbon. 
Biological, chemical, and physical methods are the conventional processes for removing organic pollutants. Owing to the antibacterial nature, CAP cannot be effectively removed by biodegradation in traditional biological treatment [11,12]. Photocatalytic degradation, radiation-induced, ozonation were reported to removal CAP [13-15]. However, these methods exhibit some disadvantages such as poor efficiency or high operational costs, and the by-products of CAP might be more toxic for human health $[15,16]$. For instance, photocatalytic degradation of CAP would produce rich toxicity byproducts, which have potential carcinogenic risks for human beings and animals [17]. Adsorption, due to its simplicity and eco-friendliness, is an effective method for antibiotic removal from aqueous solution [18,19]. Porous materials have been used in CAP adsorptive removal, such as mesoporous silica, carbon nanotubes (CNTs), earth materials, bamboo charcoal (BC) and mesoporous carbon [20-24]. Although mesoporous silica and CNTs showed high CAP adsorption capacities, they exhibited potential toxicity, complex fabrication process and high cost $(\$ 120-180$ per kilogram of CNTs) [23,25]. Earth materials (e.g., kaolinite, montmorillonite and zeolites) and BC are relatively cheap and easy to obtain, but poorly adsorb CAP [22,26]. Fan et al. [26] reported a value of $3 \mathrm{mg} / \mathrm{g}$ for CAP adsorption capacity by $\mathrm{NaOH}$-modified BC, and Sun et al. [22] estimated CAP adsorption capacity of modified kaolinite of only around $0.59 \mathrm{mg} / \mathrm{kg}$. As a promising porous carbonaceous adsorbent, activated carbon has demonstrated an extraordinary adsorption capacity for removing various antibiotics due to its large surface area and highly developed pore volume $[18,24,27]$. Mohd Din et al. [24] found mesoporous carbons produced by a hard-templating method have a maximum adsorption capacity of CAP of around $209.7 \mathrm{mg} / \mathrm{g}$. Activated carbon can be produced from aquatic plants, which are widely used in constructed wetlands and obtained at no cost [18,27-29]. For this reason, aquatic plant-based activated carbon could greatly reduce the cost of preparation. Typha orientalis, a perennial aquatic plant, has a developed ventilation system and can provide large quantities of biomass [29]. Therefore, this plant is available at low cost and could offer a good precursor for the preparation of efficient porous carbon materials.

The aim of this research was to evaluate the feasibility of preparation of activated carbon by using Typha orientalis with phosphoric acid activation and the removal of CAP from aqueous solutions by the prepared activated carbon. The physicochemical properties of activated carbon and CAP adsorption mechanisms were investigated by $\mathrm{N}_{2}$ adsorption/desorption isotherms, Boehm's titration, XPS analysis, batch adsorption experiments and desorption experiments. Furthermore, the CAP adsorption performance of the prepared activated carbon in a realistic water environment was evaluated.

\section{Materials and Methods}

\subsection{Materials}

The CAP (purity $>98 \%$ ) used in this work was purchased from Sangon Biotech Co., Ltd. (Shanghai, China). The molecular structure and properties of CAP are shown in Figure 1 and Table 1. Naphthalene (98\%) and 2,4-dinitrotoluene (>99\%) were purchased from Aladdin (Shanghai, China). All other chemical reagents were of analytical reagent grade. The dry Typha orientalis (TO) was collected from a wetland in Jinan, Shandong, China. TO was washed with distilled water to remove impurities, then dried at $105{ }^{\circ} \mathrm{C}$ for $24 \mathrm{~h}$, smashed and screened to 40 -mesh particle size by standard sieves (Model $\Phi 200$ ) to serve as a precursor for the preparation of activated carbon.

Table 1. Properties of CAP.

\begin{tabular}{ccccc}
\hline Compound & Chemical Formula & Molecular Weight & $\log \boldsymbol{K}_{\text {ow }}$ [23] & p $\boldsymbol{K}_{\mathbf{a}}$ [30] \\
\hline $\mathrm{CAP}$ & $\mathrm{C}_{11} \mathrm{H}_{12} \cdot \mathrm{C}_{12} \mathrm{O}_{5} \mathrm{~N}_{2}$ & 323.13 & 1.14 & 11.03 \\
\hline \multicolumn{5}{c}{ Notes: $\log K_{\text {ow }}$, octanol-water partition coefficient. }
\end{tabular}




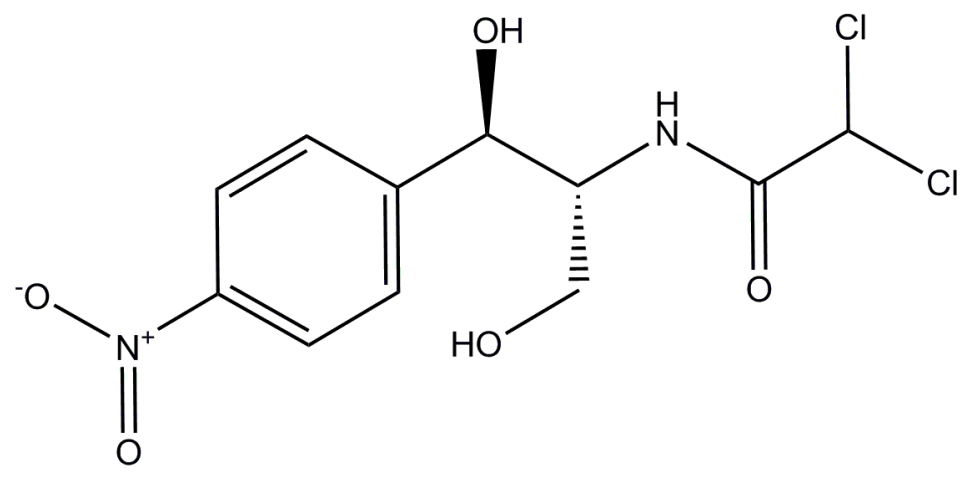

Figure 1. Molecular structure of CAP.

\subsection{Preparation of Activated Carbon}

Activated carbon (AC) was prepared by phosphoric acid activation. TO (10 g) was adequately impregnated with $\mathrm{H}_{3} \mathrm{PO}_{4}$ solution ( $85 \mathrm{wt}$. \%) at a ratio of 2.5/1 $\left(\mathrm{g} \mathrm{H}_{3} \mathrm{PO}_{4} / \mathrm{g} \mathrm{TO}\right)$ for $12 \mathrm{~h}$ at room temperature. After impregnation, the liquid mixture was directly put into a muffle furnace and heated to $450{ }^{\circ} \mathrm{C}$ for $1 \mathrm{~h}$ for activation treatment. Then, the product was washed with distilled water until the $\mathrm{pH}$ of the filtrate stabilized. Finally, the samples were filtered and dried at $105^{\circ} \mathrm{C}$ for $10 \mathrm{~h}$, then ground and sieved to 100-200-mesh using standard sieves.

\subsection{Characterization of Activated Carbon}

The specific surface area and pore size distribution of AC before and after CAP adsorption were determined by $\mathrm{N}_{2}$ adsorption/desorption isotherms at $77 \mathrm{~K}$ with a surface area analyzer (Quantachrome Corporation, Boynton Beach, FL, USA). Before $\mathrm{N}_{2}$ adsorption analysis, all samples were degassed at room temperature for $12 \mathrm{~h}$ to avoid thermal decomposition of adsorbed CAP. The specific surface area $\left(S_{\mathrm{BET}}\right)$ was calculated by the Brunauer-Emmett-Teller $(\mathrm{BET})$ method, and pore size distribution was determined by the Density Functional Theory (DFT) method. Total pore volume $\left(V_{\text {tot }}\right)$ was determined from the volume of $\mathrm{N}_{2}$ adsorbed at $\mathrm{P} / \mathrm{P}_{0}=0.95$. Micropore surface area $\left(S_{\text {mic }}\right)$, external surface area $\left(S_{\text {ext }}\right)$ and micropore volume $\left(V_{\text {mic }}\right)$ were obtained via t-plot analysis. Average pore diameter $\left(D_{\mathrm{p}}\right)$ was calculated from $D_{\mathrm{p}}=4 V_{\text {tot }} / S_{\mathrm{BET}}[31]$.

The surface functional groups on AC were quantified by Boehm's titration method [32]. The $\mathrm{pH}$ at the point of zero charge $\left(\mathrm{pH}_{\mathrm{pzc}}\right)$ of $\mathrm{AC}$ was estimated using the batch equilibrium method developed by Noh and Schwarz [33]. The surface binding state and elemental speciation of AC were analyzed by X-ray photoelectron spectroscopy (XPS) (Perkin-Elmer PHI 550 ESCA/SAM, Perkin-Elmer, Norwalk, $\mathrm{CA}, \mathrm{USA}$ ) with $\mathrm{Mg} \mathrm{K} \alpha$ irradiation ( $1486.71 \mathrm{eV}$ of photons) as the $\mathrm{X}$-ray source. All binding energies were referenced to the $\mathrm{C} 1 \mathrm{~s}$ peak at $284.6 \mathrm{eV}$ to compensate for the surface charging effects.

\subsection{Adsorption Experiments}

All batch adsorption experiments were performed in 150-mL stoppered conical flasks containing $30 \mathrm{mg}$ AC mixed with $50 \mathrm{~mL}$ CAP solution. The initial $\mathrm{pH}$ of the CAP solution was adjusted with $0.1 \mathrm{M} \mathrm{HCl}$ or $\mathrm{NaOH}$ solution and measured with a pH meter (Model pHS-3C, Leici Equipment Factory, Shanghai, China). The ionic strength was adjusted with $\mathrm{NaCl}$ solution. The samples were shaken at $25^{\circ} \mathrm{C}$ and $120 \mathrm{rpm}$ in a thermostated shaker bath (model THZ-82B, Jintan Medical Instrument Factory, Jintan, China) for $48 \mathrm{~h}$ to ensure adsorption equilibrium. After equilibrium, the samples were filtered through a $0.45-\mu \mathrm{m}$ membrane filter, and the concentration of CAP in the filtrate was analyzed by a UV-vis spectrophotometer (UV-5100, Shanghai Metash Instruments Factory, Shanghai, China) at a maximum wavelength of $278 \mathrm{~nm}$ [24].

For isotherm studies, the CAP adsorption capacity was evaluated within the initial CAP concentration in a range of $0.1-0.3 \mathrm{mmol} / \mathrm{L}$ at different ionic strengths $(0,50$ and $500 \mathrm{mM} \mathrm{NaCl})$. 
The maximum CAP adsorption capacity of commercial carbon F400 (Calgon, Pittsburgh, PA, USA) was also studied to compare with AC.

The influence of $\mathrm{pH}$ on the removal of $\mathrm{CAP}$ by $\mathrm{AC}$ was performed under a $\mathrm{pH}$ range of 2.0-8.0 at $0.2 \mathrm{mmol} / \mathrm{L}$ CAP solution.

The adsorption capacity and removal efficiency of CAP were calculated according to Equations (1) and (2):

$$
\begin{gathered}
Q_{e}=\frac{\left(C_{0}-C_{e}\right) V}{W} \\
\text { \%removal }=\frac{100\left(C_{0}-C_{e}\right)}{C_{0}}
\end{gathered}
$$

where $Q_{e}$ is the adsorption capacity $(\mathrm{mmol} / \mathrm{g}), C_{0}$ and $C_{e}$ is the initial and equilibrium CAP concentration (mmol/L); $V$ is the solution volume $(\mathrm{L}) ; W$ is the mass of adsorbent $(\mathrm{g})$.

For kinetic studies, $0.6 \mathrm{~g}$ AC was added to 1 -L CAP solutions $(0.15,0.2$ and $0.3 \mathrm{mmol} / \mathrm{L})$ in a set of beakers and agitated with an electromagnetic stirrer (Model 78-1, Huanyu Science Instrument Factory, Wenzhou, China) at $400 \mathrm{rpm}$ at $25^{\circ} \mathrm{C}$. Then, $20 \mathrm{~mL}$ of each sample was taken out at predetermined time intervals and filtered through a $0.45-\mu \mathrm{m}$ membrane filter (Xinya Purifier Devices Factory, Shanghai, China) for CAP concentration analysis.

Competition adsorption of CAP and two neutral compounds, 2,4-dinitrotoluene (2,4-DNT) and naphthalene, was tested. The experiments were carried out at initial $\mathrm{pH} 2.5$, with initial respective concentrations of CAP, 2,4-DNT and naphthalene of $0.1 \mathrm{mmol} / \mathrm{L}, 0.05 \mathrm{mmol} / \mathrm{L}$ and $0.05 \mathrm{mmol} / \mathrm{L}$.

All experiments were done in triplicate. The averages were used with the relative error below $5 \%$.

\subsection{Desorption Experiments}

An adsorption experiment was performed at a 0.2-mmol/L CAP solution ( $\mathrm{pH}$ 6.35) as described above. Then, desorption experiments were carried out immediately after the adsorption experiments. The samples were centrifuged, and the activated carbon was washed with distilled water to remove unabsorbed CAP. Then, the activated carbon was mixed with $50 \mathrm{~mL}$ of different solutions: (a) distilled water, (b) $0.01 \mathrm{M} \mathrm{NaCl}$; (c) $1 \mathrm{M} \mathrm{NaCl}$; (d) $0.1 \mathrm{M} \mathrm{NaOH}$; and (e) $95 \%$ ethanol. The simples were shaken at $120 \mathrm{rpm}$ (room temperature) for $48 \mathrm{~h}$. After equilibrium, the samples were filtered and the CAP concentration analyzed. All experiments were done in triplicate. The averages were used with the relative error below $5 \%$.

\subsection{Adsorption of CAP in Realistic Water Environment}

Groundwater was collected from Jinan Water Group Co., Ltd. (Jinan, China), and treated wastewater was collected from the Second Wastewater Treatment Plant of Everbright Water (Jinan) Ltd. (Jinan, China). The water samples were filtered through 1.2- $\mu \mathrm{m}$ filter paper and characterized by the standard methods [34]. The adsorption experiments were carried out by adding $30 \mathrm{mg} \mathrm{AC}$ to $50 \mathrm{~mL}$ of water (i.e., distilled water, groundwater and treated wastewater) spiked with $0.2 \mathrm{mmol} / \mathrm{L}$ $\mathrm{CAP}$ and shaken at $25^{\circ} \mathrm{C}$ and $120 \mathrm{rpm}$ in a thermostated shaker bath (model THZ-82B, Jintan Medical Instrument Factory, Jintan, China) for $48 \mathrm{~h}$ to ensure adsorption equilibrium. All experiments were done in triplicate. The averages were used with the relative error below $5 \%$.

\section{Results and Discussion}

\subsection{Physical and Chemical Properties of AC}

Adsorbent porosity is an important factor of the adsorption capacity of activated carbon. $\mathrm{N}_{2}$ adsorption/desorption isotherms and pore size distribution of AC are illustrated in Figure 2. The textural parameters and yield of AC were calculated and summarized in Table 2. The yield of AC was $40.03 \%$. According to the Figure 2, a type IV isotherm was observed, which had a wide hysteresis loop at high relative pressures [35]. AC had a mixed microporous and mesoporous structure. 
Additionally, the pore size distribution curve (Figure 2) showed the pores of AC were mostly located in the mesoporous $\left(2-20 \mathrm{~nm}\right.$ ) range. The average pore diameter of AC was $6.37 \mathrm{~nm}$. The $S_{\text {BET }}$ was $794.8 \mathrm{~m}^{2} / \mathrm{g}$, with a $V_{\text {tot }}$ of $1.266 \mathrm{~cm}^{3} / \mathrm{g}$, and the contribution of micropore to the total pore volume was $12.2 \%$, reflecting a mostly mesoporous structure of AC. The adsorbent porosity can affect adsorption of antibiotics through the pore effect (e.g., pore filling or size exclusion) depending on the geometry of the adsorbate molecules [36]. The adsorbate with the molecular size similar to the micropore diameter will be preferentially adsorbed on activated carbon, and the size-exclusion effect will occur when the pore diameter is smaller than approximately 1.7 times the molecule's second-widest dimension [37]. The presence of mesoporous could increase the diffusion rate of adsorbate molecules in the particles. The geometry of the CAP molecule $(3.93 \times 8.30 \times 11.03 \AA$, calculated using Gaussian 09 software, Gaussian Inc., Wallingford, CT, USA) was smaller than the width of micropores ( $<2 \mathrm{~nm})$. In the CAP adsorption process, mesopores provided channels for CAP species to diffuse into the internal pores of $\mathrm{AC}$, and then CAP was adsorbed on AC by micropore-filling and chemical reaction. The contribution of porosity in CAP adsorption was also investigated, the pore size distribution and textural parameters of AC before and after CAP adsorption are compared in Figure 2 and Table 2. Obviously, both micropores and mesopores of AC were occupied by CAP molecules. The volume of pores with diameters around 1.0-1.3 nm (consistent with the size of CAP) was obviously smaller after CAP adsorption, implying micropore-filling occurred. The adsorption sites existed in the mesoporous spaces were efficiently combined with the CAP, reducing the mesoporous volume. As a result, the pore structure of AC could be conducive to rapid adsorption of CAP.

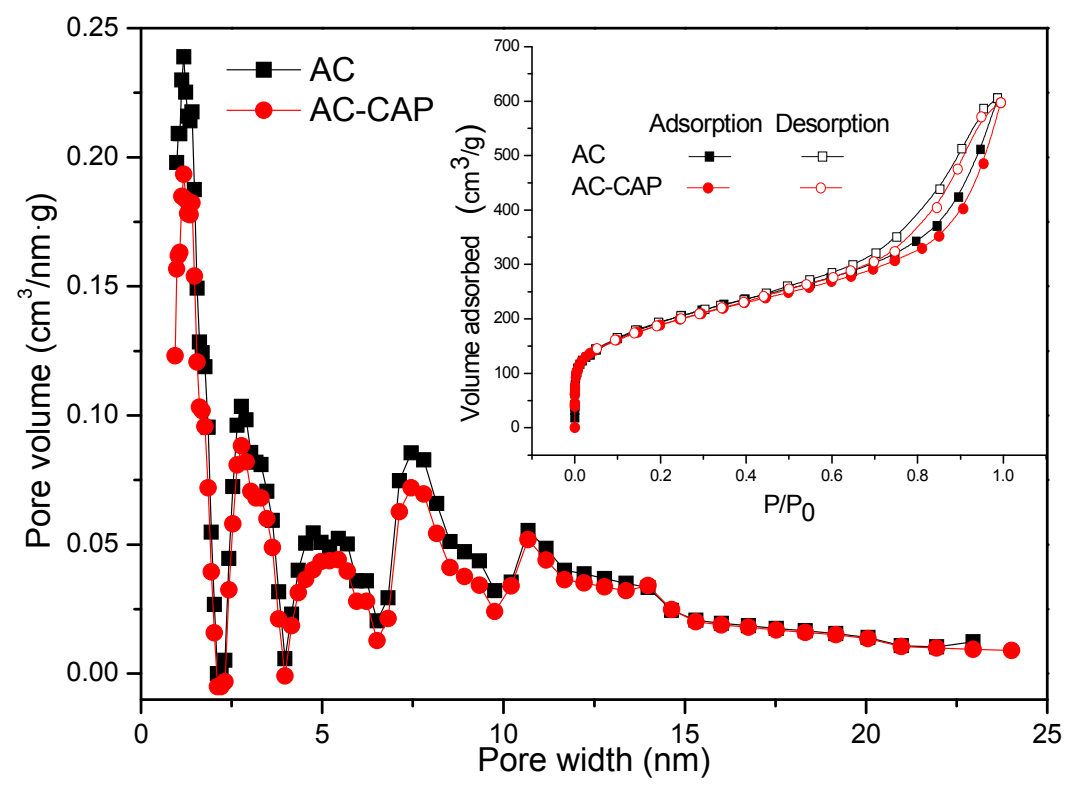

Figure 2. Pore size distribution and $\mathrm{N}_{2}$ adsorption/desorption isotherm (insert) of AC before CAP adsorption and AC after CAP adsorption (AC-CAP). The pore size distribution was determined by the Density Functional Theory (DFT) method.

Table 2. The yield and textural characterization before and after CAP adsorption of AC.

\begin{tabular}{|c|c|c|c|c|c|c|c|c|}
\hline Sample & $\begin{array}{l}S_{B E T}{ }^{a} \\
\left(m^{2} / g\right)\end{array}$ & $\begin{array}{l}S_{\text {ext }} b \\
\left(\mathrm{~m}^{2} / g\right)\end{array}$ & $\begin{array}{l}S_{m i c} b \\
\left(m^{2} / g\right)\end{array}$ & $\begin{array}{c}V_{\text {tot }} \mathrm{c} \\
\left(\mathrm{cm}^{3} / \mathrm{g}\right)\end{array}$ & $\begin{array}{l}V_{\text {mic }} b \\
\left(\mathrm{~cm}^{3} / g\right)\end{array}$ & $\begin{array}{c}\mathrm{V}_{\text {mic }} / \mathrm{V}_{\text {tot }} \\
(\%)\end{array}$ & $\begin{array}{l}D_{p}{ }^{d} \\
(n m)\end{array}$ & $\begin{array}{c}\text { Yield } \\
(\%)\end{array}$ \\
\hline $\mathrm{AC}$ & 794.8 & 543.4 & 251.4 & 1.266 & 0.154 & 12.2 & 6.37 & 40.03 \\
\hline AC-CAP & 672.3 & 503.8 & 168.5 & 1.136 & 0.106 & 9.3 & 5.51 & - \\
\hline
\end{tabular}

Notes: ${ }^{\text {a }} S_{\text {BET }}$ (BET surface area) was calculated by the Brunauer-Emmett-Teller (BET) method; ${ }^{\text {b }} S_{\text {ext }}$ (External surface area), $S_{\text {mic }}$ (Micropore area) and $V_{\text {mic }}$ (Micropore volume) were obtained via $t$-plot analysis. ${ }^{c} V_{\text {tot }}$ was calculated for $\mathrm{P} / \mathrm{P}_{0}=0.95 .{ }^{\mathrm{d}} D_{\mathrm{p}}$ (average pore diameter) was calculated by $D_{\mathrm{p}}=4 V_{\text {tot }} / S_{\mathrm{BET}}$. 
To verify the identity and quantity functional groups on AC, Boehm's titration was conducted (Table 3). The majority of the oxygen functional groups were acidic $(2.078 \mathrm{mmol} / \mathrm{g})$, accounting for $67.62 \%$ of the total functional groups. Carboxyl, lactone and phenolic groups were $0.695,0.596$ and $0.787 \mathrm{mmol} / \mathrm{g}$, respectively. The basic groups were $0.995 \mathrm{mmol} / \mathrm{g}$. Therefore, the activated carbon was acidic. The $\mathrm{pH}$ of point of zero charge $\left(\mathrm{pH}_{\mathrm{pzc}}\right)$ of $\mathrm{AC}$ was 6.03 , which coincided with the results of Boehm's titration. The O-containing groups on AC can act as hydrogen bond donor and acceptor sites to connect CAP molecules via hydrogen-bonding interaction. Phenolic groups on carbon material serve as electron-donating groups promoting the $\pi-\pi$ electron-donor-acceptor (EDA) interaction between the aromatic ring of CAP and graphite structure of carbon material. Therefore, the effective CAP adsorption sites can be provided by these functional groups on AC surface.

Table 3. $\mathrm{pH}_{\mathrm{pzc}}$ and concentrations of surface functional groups of AC.

\begin{tabular}{cccccccc}
\hline Sample & $\begin{array}{c}\text { Carboxyl } \\
(\mathbf{m m o l} / \mathbf{g})\end{array}$ & $\begin{array}{c}\text { Lactone } \\
(\mathbf{m m o l} / \mathbf{g})\end{array}$ & $\begin{array}{c}\text { Phenolic } \\
\mathbf{( m m o l} / \mathbf{g})\end{array}$ & $\begin{array}{c}\text { Total Acidic } \\
(\mathbf{m m o l} / \mathbf{g})\end{array}$ & $\begin{array}{c}\text { Total Base } \\
(\mathbf{m m o l} / \mathbf{g})\end{array}$ & $\begin{array}{c}\text { Total Groups } \\
\mathbf{( m m o l / g )}\end{array}$ & $\mathbf{p H}_{\mathbf{p z c}}$ \\
\hline AC & 0.695 & 0.596 & 0.787 & 2.078 & 0.995 & 3.073 & 6.03 \\
$\% /$ total groups & 22.62 & 19.39 & 25.61 & 67.62 & 32.38 & - & - \\
\hline
\end{tabular}

\subsection{Adsorption Kinetics}

The influence of contact time on CAP adsorption at three different initial concentrations by AC is presented in Figure 3. Similar trends were observed at all three CAP concentrations; the adsorption of CAP increased rapidly and reached the $90 \%$ maximum adsorption capacity within $1 \mathrm{~h}$ due to the abundant vacant adsorption sites on AC at the initial stage. Then, CAP adsorption tended to slow, which could be caused by the increase in diffusion resistance and the repulsive forces between the CAP molecules adsorbed on AC and in the solute phase. The equilibrium time reached $6 \mathrm{~h}$ (Figure $3 \mathrm{~b}$ ), and the equilibrium CAP adsorption capacities were $0.215,0.265$ and $0.320 \mathrm{mmol} / \mathrm{g}$ for initial CAP concentrations of $0.15,0.2,0.3 \mathrm{mmol} / \mathrm{L}$, respectively. Therefore, $48 \mathrm{~h}$ could ensure adsorption equilibrium for CAP adsorption. The higher CAP adsorption capacity of AC at high initial concentration was possible due to enhancement of the driving force between the aqueous and solid phase, which allowed the collision of CAP molecules and adsorption sites.
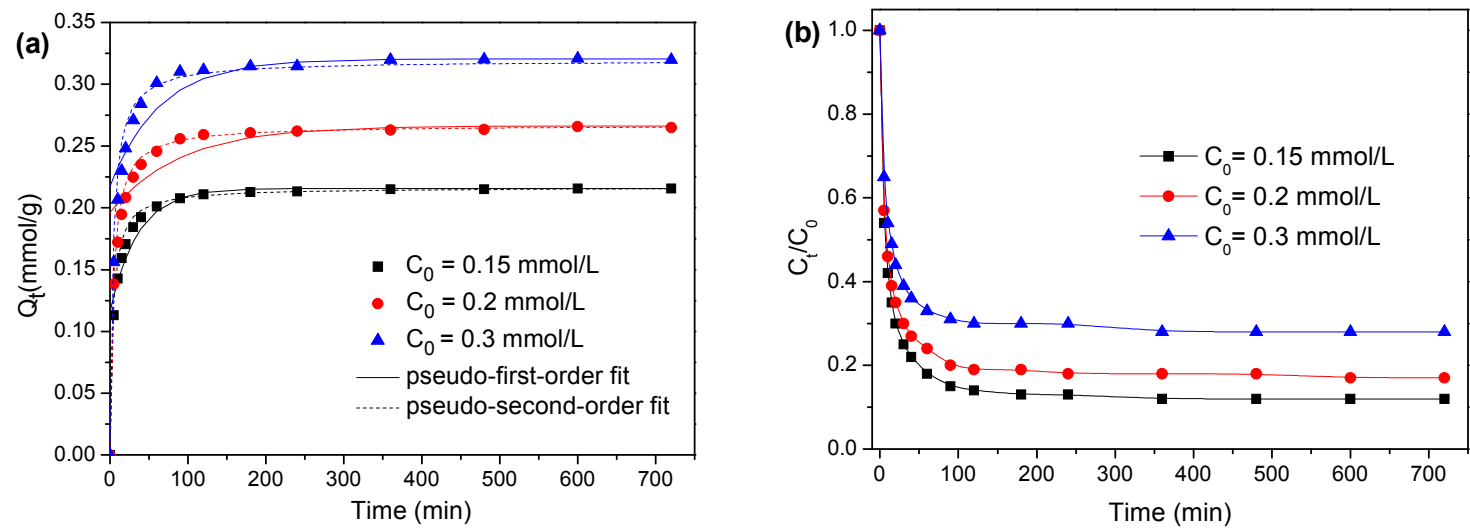

Figure 3. Adsorption kinetics (a) and $C_{t} / C_{0}$ versus time (b) of CAP on AC (dosage $=30 \mathrm{mg} / 50 \mathrm{~mL}$, temperature $=25^{\circ} \mathrm{C}, \mathrm{pH}=6.20 \pm 0.2$ ).

In order to identify the adsorption mechanism of CAP and the main rate-controlling steps, the pseudo-first-order kinetic model [38], and pseudo-second-order kinetic model [39] were used to study the adsorption kinetics. Their equations are expressed as follow:

$$
\ln \left(Q_{e}-Q_{t}\right)=\ln Q_{e}-k_{1} t
$$




$$
\frac{t}{Q_{t}}=\frac{1}{k_{2} Q_{e}^{2}}+\frac{1}{Q_{e}} t
$$

where $Q_{e}$ and $Q_{t}(\mathrm{mg} / \mathrm{g})$ are the amounts of the adsorbates in the adsorbent at equilibrium and at time $t(\mathrm{~min})$, respectively, $k_{1}\left(\mathrm{~min}^{-1}\right)$ is the pseudo-first-order adsorption rate constant, and $k_{2}(\mathrm{~g} /(\mathrm{mg} \cdot \mathrm{min}))$ is the pseudo-second-order adsorption rate constant.

The calculated parameters and correlation coefficients are listed in Table 4. The pseudo-second-order kinetic model fitted the experimental data better than the pseudo-first-order kinetic model. It had a higher $R^{2}(>0.999)$ and showed better agreements between $Q_{e}(\mathrm{cal})$ and $Q_{e}(\exp )$. The adsorption of $\mathrm{CAP}$ on AC that was described by a pseudo second-order kinetic model implied a chemical controlling step, indicating the reactions involved valency forces via sharing or exchanging electrons between the surface functional groups on AC and CAP molecules [39]. Similar observations on adsorption kinetic for other carbon materials have been reported in the literature [24,40,41]. Qin et al. [40] suggested that chemical adsorption was the rate-controlling step of CAP adsorption on porous carbon because the kinetic data fitted a pseudo-second-order kinetic model. Mohd Din et al. [24] reported that adsorption of CAP on mesoporous carbons followed a pseudo-second-order kinetic model, and the possible CAP adsorption mechanism was a $\pi-\pi$ interaction. Therefore, adsorption of CAP on AC prepared in this work was related to chemisorption.

Table 4. Pseudo-first-order and pseudo-second-order kinetic parameters for CAP adsorption on AC.

\begin{tabular}{cccccccc}
\hline \multirow{2}{*}{$\begin{array}{c}C_{\mathbf{0}} \\
(\mathbf{m m o l} / \mathrm{L})\end{array}$} & $\begin{array}{c}Q_{e}(\mathbf{e x p}) \\
(\mathbf{m m o l} / \mathbf{g})\end{array}$ & $\begin{array}{c}\mathbf{Q}_{\boldsymbol{e}}(\mathbf{c a l}) \\
(\mathbf{m m o l} / \mathbf{g})\end{array}$ & $\begin{array}{c}\boldsymbol{k}_{\mathbf{1}} \\
\left(\mathbf{m i n}^{-1}\right)\end{array}$ & $\boldsymbol{R}^{\mathbf{2}}$ & $\begin{array}{c}\boldsymbol{Q}_{\boldsymbol{e}}(\mathbf{c a l}) \\
(\mathbf{m m o l} / \mathbf{g})\end{array}$ & $\begin{array}{c}\boldsymbol{k}_{\mathbf{2}} \\
\mathbf{( g / m g} \cdot \mathbf{m i n})\end{array}$ & $\boldsymbol{R}^{\mathbf{2}}$ \\
\hline 0.15 & 0.215 & 0.0100 & 0.0282 & 0.9122 & 0.216 & 0.0143 & 0.9999 \\
0.2 & 0.265 & 0.0702 & 0.0112 & 0.7532 & 0.266 & 0.0116 & 0.9999 \\
0.3 & 0.320 & 0.0935 & 0.0157 & 0.7854 & 0.318 & 0.0097 & 0.9999 \\
\hline
\end{tabular}

Notes: $C_{0}$ is the initial concentration of CAP. $Q_{e}(\exp )$ is the experimental value of adsorption capacity at equilibrium. $Q_{e}$ (cal) is the theoretical values of adsorption capacity calculated from the pseudo-first-order/pseudo-second-order kinetic model. $k_{1}$ is the pseudo-first-order adsorption rate constant. $k_{2}$, the pseudo-second-order adsorption rate constant.

\subsection{Adsorption Isotherms}

Equilibrium data for CAP adsorption onto AC at various ionic strengths $(0,50$ and $500 \mathrm{mM} \mathrm{NaCl})$ were analyzed by the Langmuir and Freundlich models [42,43]; the equations are expressed as follows:

$$
\begin{gathered}
Q_{e}=Q_{m} K_{L} C_{e} /\left(1+K_{L} C_{e}\right) \\
\left(Q_{m}=K_{F} C_{e}^{1 / n}\right)
\end{gathered}
$$

where $C_{e}(\mathrm{mg} / \mathrm{L})$ is the equilibrium concentration of CAP; $Q_{e}(\mathrm{mg} / \mathrm{g})$ is the adsorption capacity of CAP at equilibrium; $Q_{m}(\mathrm{mg} / \mathrm{g})$ is the maximum adsorption capacity; $K_{L}(\mathrm{~L} / \mathrm{mg})$ is the Langmuir constant; $K_{F}\left(\mathrm{mg} / \mathrm{g}(\mathrm{L} / \mathrm{mg})^{1 / n}\right)$ is the Freundlich affinity coefficient, and $1 / n$ is the Freundlich linearity index.

The adsorption isotherms of CAP onto AC are shown in Figure 4, and the constants calculated by the Langmuir and Freundlich equations are summarized in Table 5. The values of the correlation coefficient $\left(R^{2}\right)$ derived from both the Langmuir and Freundlich model were greater than 0.98, indicating that the equilibrium data were simulated well by both models. However, the Freundlich model with a higher $R^{2}$ and better representation of the data seemed to be more applicable than the Langmuir model, reflecting CAP adsorption on the heterogeneous surface of AC. For the three different ionic strengths, the $1 / n$ values were smaller than 1 , representing a high adsorption affinity of CAP on AC.

It is important to investigate the effect of ionic strength (I) on CAP adsorption of AC, since wastewater usually contains large amounts of ions. The experiments were conducted at three 
different $\mathrm{NaCl}$ concentrations $(I=0,50$ and $500 \mathrm{mM})$. High ionic strength can weaken the electrostatic interaction between ionic compounds and charged functional group on activated carbon by a screening effect, thus affecting the adsorption [21]. As shown in Figure 4, the adsorption capacity of CAP on AC was insensitive to ionic strength variation, which is consistent with the slight variation of $Q_{m}$ and $K_{F}$ values at three different ionic strengths. This observation indicated that electrostatic interactions were not significant in CAP adsorption on AC.

Table 5. Langmuir and Freundlich isotherm parameters for CAP adsorption by AC.

\begin{tabular}{|c|c|c|c|c|c|c|c|}
\hline \multirow[b]{2}{*}{ Sample } & \multirow[b]{2}{*}{$\begin{array}{c}\text { Ionic Strength } \\
(\mathrm{mM})\end{array}$} & \multicolumn{3}{|c|}{ Langmuir } & \multicolumn{3}{|c|}{ Freundlich } \\
\hline & & $\begin{array}{c}Q_{m} \\
(\mathrm{mmol} / \mathrm{g})\end{array}$ & $\begin{array}{c}K_{L} \\
(\mathrm{~L} / \mathrm{mmol})\end{array}$ & $R^{2}$ & $\begin{array}{c}K_{F}\left(\mathrm{mmol}^{1-1 / n}\right. \\
\left.\mathrm{L}^{1 / n} / \mathrm{g}\right)\end{array}$ & $1 / n$ & $R^{2}$ \\
\hline \multirow{3}{*}{$\mathrm{AC}$} & 0 & 0.424 & 58.2 & 0.9888 & 0.118 & 0.343 & 0.9979 \\
\hline & 50 & 0.407 & 61.2 & 0.9903 & 0.117 & 0.336 & 0.9959 \\
\hline & 500 & 0.424 & 65.5 & 0.9893 & 0.123 & 0.432 & 0.9983 \\
\hline
\end{tabular}

Notes: $Q_{m}$ is the maximum adsorption capacity. $K_{L}$ is the Langmuir constant. $K_{F}$ is the Freundlich affinity coefficient. $1 / n$ is the Freundlich linearity index.

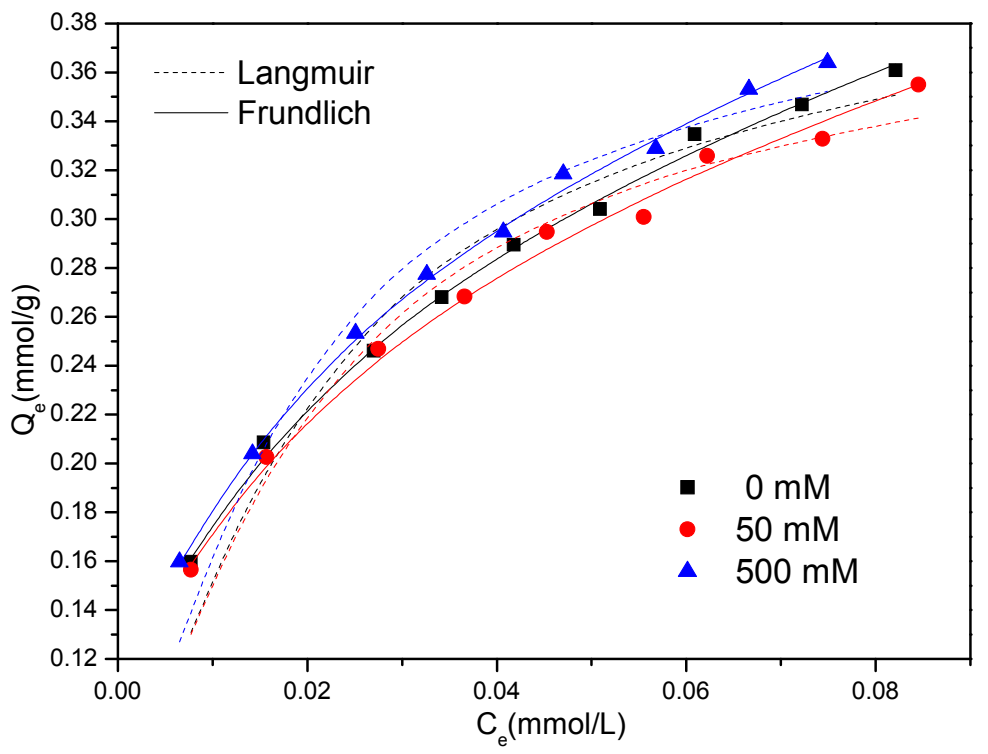

Figure 4. Adsorption isotherms of CAP for AC at three different ionic strengths fit by the Langmuir model (dashed lines) and Freundlich model (solid lines) $\left(C_{0}=0.1-0.3 \mathrm{mmol} / \mathrm{L}\right.$, dosage $=30 \mathrm{mg} / 50 \mathrm{~mL}$, temperature $=25^{\circ} \mathrm{C}, \mathrm{pH}=6.20 \pm 0.2$, time $=24 \mathrm{~h}$ ).

\subsection{Effect of the Initial $p H$}

The initial $\mathrm{pH}$ is one of the most significant factors in adsorption since it affects the degree of ionization of adsorbate and functional groups on the surface of activated carbon. The initial testing was performed at $\mathrm{pH} 2$ to $\mathrm{pH} 8$, as CAP is hydrolyzed at $\mathrm{pH}<2$ or $\mathrm{pH}>8$ [44,45]. The hydrolytic reactions of $\mathrm{CAP}$ at $\mathrm{pH}<2$ or $\mathrm{pH}>8$ and fraction of CAP species are illustrated in Figure $5 \mathrm{~b}, \mathrm{c}$.

The effect of $\mathrm{pH}$ on CAP adsorption onto AC is shown in Figure 5a. The CAP removal efficiency decreased from $87.8 \%$ to $81.4 \%$ as the initial $\mathrm{pH}$ increased from 2 to 8 . CAP removal was less correlated with initial $\mathrm{pH}$. It implied that the variation of $\mathrm{H}^{+}$concentration and surface charges of $\mathrm{AC}$ had no obvious effect on CAP adsorption. The $\mathrm{pH}_{\mathrm{pzc}}$ of $\mathrm{AC}$ was 6.03. Although the acidic functional groups of $\mathrm{AC}$ progressively ionized with the increase in $\mathrm{pH}$, it did not considerably influence CAP adsorption. This is because the $\mathrm{p} K_{\mathrm{a}}$ of CAP is 11.03 [30], and CAP molecules existed mainly in neutral form in this study (Figure $5 b$ ). There was a slight electrostatic interaction between CAP molecules and the surface 
of $\mathrm{AC}$, and cation exchange rarely occurred in CAP adsorption. Hence, electrostatic interaction and ion exchange were scarcely responsible for adsorption of CAP on AC. The main adsorption interaction of CAP on AC might be the $\pi-\pi$ EDA interaction, hydrophobic interaction and hydrogen-bonding interaction. At low $\mathrm{pH}$ conditions, a hydrogen bond could be produced between $\mathrm{N}-\mathrm{H},-\mathrm{OH},-\mathrm{NO}_{2}$ groups in $\mathrm{CAP}$ and $-\mathrm{OH},-\mathrm{COOH}, \mathrm{C}=\mathrm{O}$ groups on $\mathrm{AC}$. With increased $\mathrm{pH}$, some of acidic functional groups on $\mathrm{AC}$ were ionized, and $\mathrm{H}_{2} \mathrm{O}$ competed with $\mathrm{CAP}$ molecules for charged functional groups. The competition of $\mathrm{H}_{2} \mathrm{O}$ and CAP gradually weakened the hydrogen-bonding interaction between CAP and AC. Therefore, the slight decrease in CAP adsorption capacity might be caused by a weakened hydrogen-bonding interaction between $\mathrm{CAP}$ and $\mathrm{AC}$ as $\mathrm{pH}$ increased.
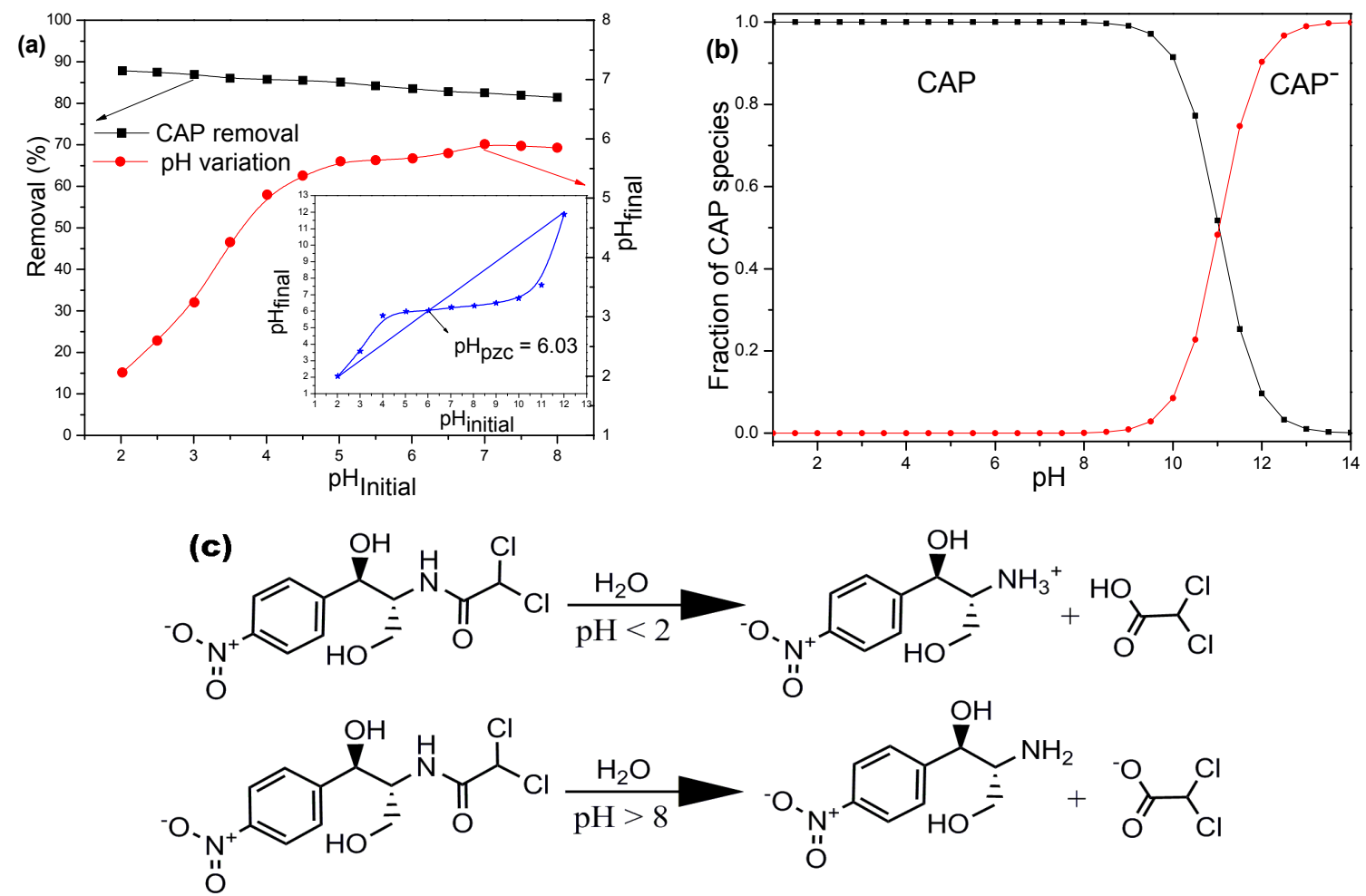

Figure 5. Effect of the initial $\mathrm{pH}$ on equilibrium $\mathrm{pH}$ and $\mathrm{CAP}$ removal on $\mathrm{AC}$, and $\mathrm{pH}_{\mathrm{pzc}}$ of $\mathrm{AC}$ (inset) (a). The fraction of CAP species (b) and the hydrolytic equation of CAP (c). $\left(\mathrm{C}_{0}=0.2 \mathrm{mmol} / \mathrm{L}\right.$, dosage $=30 \mathrm{mg} / 50 \mathrm{~mL}$, time $=24 \mathrm{~h}$, temperature $=25^{\circ} \mathrm{C}$ ).

\subsection{Desorption Experiment}

In order to gain insight into the adsorption mechanism and interactions between CAP and AC, desorption experiments were carried out. The results are summarized in Table 6 . A total of $10.6 \%$ of the adsorbed CAP was desorbed with distilled water, implying that physisorption (e.g., van der Waals interaction, and pore-filling effect) had occurred. The physisorption do not play a significant role in CAP adsorption. The desorption of CAP was less than $16 \%$ with $\mathrm{NaCl}$ solutions, a slightly higher desorption efficiency than that with distilled water. This indicated an insignificant electrostatic interaction between CAP molecules and the AC surface. More than $58 \%$ of the adsorbed CAP was recovered by $0.1 \mathrm{M} \mathrm{NaOH}$ solution, suggesting a high contribution of chemical interactions to CAP adsorption. The hydrophobic interaction was evaluated by CAP desorption using $95 \%$ ethanol. About $39.5 \%$ of adsorbed CAP was recovered by ethanol, suggesting that hydrophobic interactions were also important in CAP adsorption onto AC. 
Table 6. Percentage of adsorbed CAP mass desorbed by various treatments.

\begin{tabular}{cccccc}
\hline Desorption Treatment & Distilled Water & $\mathbf{0 . 0 1} \mathbf{~ M ~ N a C l}$ & $\mathbf{1} \mathbf{~ M ~ N a C l}$ & $\mathbf{0 . 1} \mathbf{~ M ~ N a O H}$ & $\mathbf{9 5 \%}$ Ethanol \\
\hline Desorption efficiency & $10.6 \%$ & $12.7 \%$ & $15.7 \%$ & $58.1 \%$ & $39.5 \%$ \\
\hline
\end{tabular}

\subsection{Mechanism for CAP Adsorption on the AC}

In order to further understand the mechanisms of CAP adsorption, the AC before and after CAP adsorption $(0.3 \mathrm{mmol} / \mathrm{L})$ was analyzed with XPS. The XPS survey spectra, $\mathrm{O} 1 \mathrm{~s}$ and $\mathrm{C} 1 \mathrm{~s}$ peaks of AC before and after CAP adsorption are illustrated in Figure 6. The calculated relative contents of the surface functional carbon atoms determined by $\mathrm{C} 1 \mathrm{~s}$ spectrum are also presented in Figure $6 \mathrm{c}, \mathrm{d}$, and the calculated atomic ratios are summarized in Table 7. The major $\mathrm{C} 1 \mathrm{~s}$ peak was fitted to five curves from the following groups: graphitic structure at $284.6 \mathrm{eV}, \mathrm{C}-\mathrm{O}$ (phenol, alcohol, or ether groups) at $286.2 \mathrm{eV}, \mathrm{C}=\mathrm{O}$ (carbonyl and ether groups)at $287 \mathrm{eV}, \mathrm{O}=\mathrm{C}-\mathrm{O}$ (carboxyl or ester groups) at $288.7 \mathrm{eV}$, and $\pi->\pi^{*}$ transitions at $290.5 \mathrm{eV}[26,46,47]$.

The $\mathrm{O} / \mathrm{C} \%, \mathrm{~N} / \mathrm{C} \%$ and $\mathrm{Cl} / \mathrm{C} \%$ atomic ratios of $\mathrm{AC}$ increased after $\mathrm{CAP}$ uptake (Table 7). The $\mathrm{N} 1 \mathrm{~s}$ peak $(400 \mathrm{eV})$ and $\mathrm{Cl} 2 \mathrm{p}$ peak $(200 \mathrm{eV})$ were observed in the spectrum of AC-CAP (Figure 6a), while the peak width of $\mathrm{O} 1 \mathrm{~s}$ was significantly narrowed in the high binding energy portion, and the intensity of low binding energy portion of $\mathrm{O} 1$ s peak decreased after $\mathrm{CAP}$ uptake (Figure $6 \mathrm{~b}$ ), indicating fixation of CAP onto the AC. The variation in the carbon binding energy and ratio is shown in Figure $6 \mathrm{c}, \mathrm{d}$. After CAP adsorbed onto AC, all of the fitted $C$ 1s peaks except the $C-C$ peak were slight shifted to a higher binding energy, and the $\pi->\pi^{*}$ transitions disappeared. These changes in binding energies were caused by the decrease in electron cloud density due to the electron shift to CAP in adsorption. The results elucidated the fact that a chemical reaction occurred between the functional groups on $\mathrm{CAP}$ and the surface functional groups on $\mathrm{AC}$.
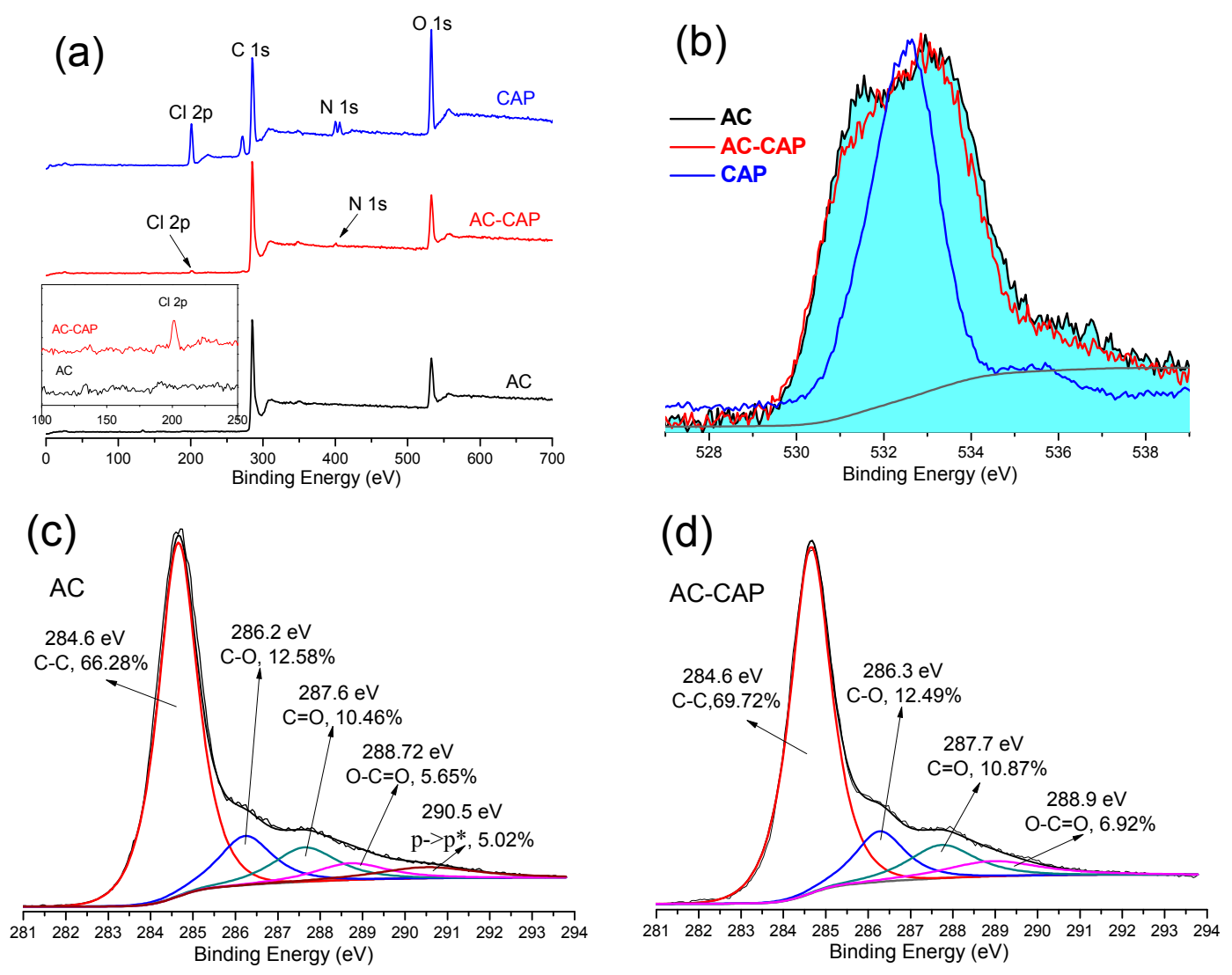

Figure 6. XPS survey spectra of AC, AC-CAP and CAP (a); O 1s (b); C 1s (c) and (d). 
Table 7. The atomic ratio of the samples.

\begin{tabular}{cccc}
\hline Sample & O/C $\%$ & N/C $\%$ & $\mathrm{Cl} / \mathrm{C} \%$ \\
\hline CAP & $97.61 \%$ & $22.97 \%$ & $36.66 \%$ \\
AC & $52.69 \%$ & $2.23 \%$ & - \\
AC-CAP & $56.51 \%$ & $5.74 \%$ & $1.69 \%$ \\
\hline
\end{tabular}

According to Figure $6 \mathrm{~b}, \mathrm{c}$, the $\pi->\pi^{*}$ transitions in the graphite structure of AC disappeared after CAP adsorption, indicating the $\pi-\pi$ EDA interaction between CAP and AC may influence adsorption. The $\pi-\pi$ EDA complexes mainly formed by the $\pi$-electron-rich polyaromatic or graphene surface of AC interacted with the $\pi$-electron-depleted aromatic rings of the adsorbates. The nitro group $\left(-\mathrm{NO}_{2}\right)$ in $\mathrm{CAP}$, a strong electron-withdrawing group, reduced the electron density of aromatic rings and served as an electron-acceptor, while the graphite structure in AC functioned as a $\pi$-electron-donor, which could benefit CAP adsorption on AC via $\pi-\pi$ EDA interaction. Moreover, phenolic groups on $\mathrm{AC}$, acting as electron-donating groups, can promote the $\pi-\pi$ EDA interaction between the aromatic ring of $\mathrm{CAP}$ and graphite structure of $\mathrm{AC}$.

To further verify the $\pi-\pi$ EDA interaction in CAP adsorption on AC, competition adsorption experiments of CAP against two neutral compounds (2,4-DNT and naphthalene) were carried out. Two neutral compounds, which have opposite quadrupole moments but comparable affinity for carbon, were chosen as competitors: 2,4 -DNT is a strong $\pi$-electron acceptor due to the electron withdraw capability of nitro groups, and naphthalene is a $\pi$-electron donor due to the rich $\pi$ electrons in aromatic rings [48]. The CAP adsorption capacities of AC in the presence of 2,4-DNT/naphthalene are illustrated in Figure 7. 2,4-DNT strongly inhibited the adsorption of CAP on AC while the competitive effect of naphthalene and CAP was insignificant. The phenomenon proved that the $\pi$-electron acceptor property of CAP is critical. As a $\pi$-electron acceptor, 2,4-DNT competed with CAP for $\pi$-electron donor sites on $\mathrm{AC}$, demonstrating that $\pi-\pi \mathrm{EDA}$ interaction played an important role in CAP adsorption on AC.

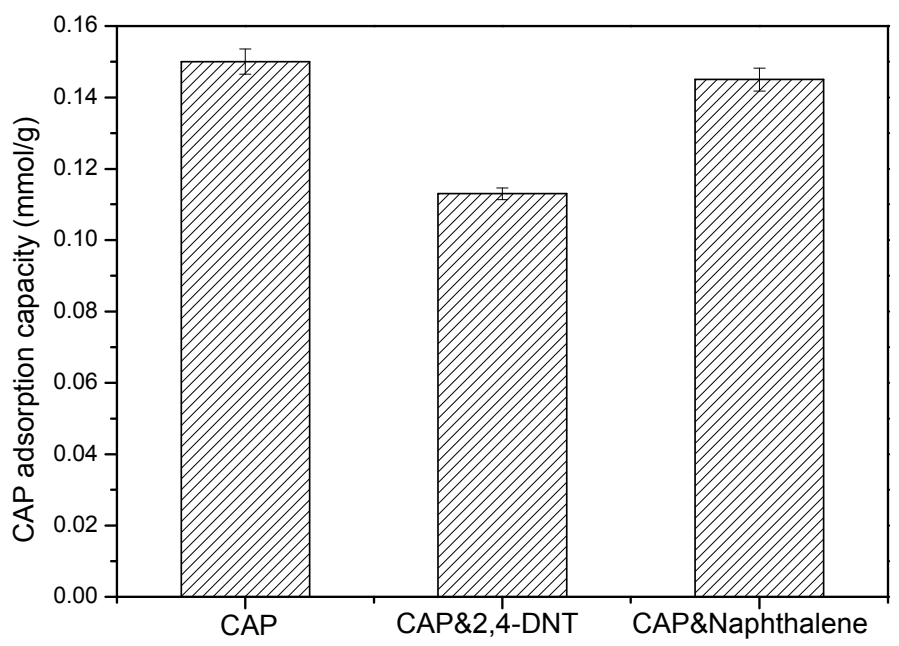

Figure 7. Competition experiments of CAP and 2,4-DNT/naphthalene adsorption on AC. (chloramphenicol concentration $=0.1 \mathrm{mmol} / \mathrm{L}, 2,4-\mathrm{DNT}$ concentration $=0.05 \mathrm{mmol} / \mathrm{L}$, naphthalene concentration $=0.05 \mathrm{mmol} / \mathrm{L}$ dosage $=30 \mathrm{mg} / 50 \mathrm{~mL}$, time $=24 \mathrm{~h}$, temperature $=25^{\circ} \mathrm{C}$ ).

According to the above analysis, the adsorption of CAP on AC involved both physical and chemical interactions. A desorption experiment by using $\mathrm{NaOH}$ indicated strong chemical interactions were involved in CAP adsorption. The dominant adsorption mechanism of CAP on AC in our study is a $\pi-\pi$ EDA interaction. As shown in XPS analysis and competition experiments, a $\pi-\pi$ EDA interaction existed between $\mathrm{CAP}$ and $\mathrm{AC}$, and exerted an influence on adsorption. This is consistent with the 
result obtained by Liao [23]. Hydrophobic interaction also played an important role in CAP adsorption, illustrating by the desorption experiment with $95 \%$ ethanol (39.5\%). Hydrogen bonding is another possible mechanism that affects the adsorption of $\mathrm{CAP}$ on $\mathrm{AC}$, considering their ionic/polar functional groups. The slight decrease in CAP removal with $\mathrm{pH}$ increase (Section 3.3) may be due to the weakened hydrogen-bonding interaction between CAP and charged functional groups on AC. Zhao et al. noted the interactions of hydrogen bonding played an important role in the adsorption of chloramphenicol in a non-ionized form onto CNTs [21]. The micropore-filling effect was proven by the comparison of pore size distribution of $\mathrm{AC}$ before and after CAP adsorption (Figure 2). In addition, desorption with distilled water $(10.6 \%)$ indicated that CAP adsorption involved a reversible physisorption via Van der Waals interaction or the micropore-filling effect. However, the effect of physisorption was unapparent. Therefore, the main adsorption mechanisms of CAP could be inferred as $\pi-\pi$ EDA interaction, hydrophobic interaction, and hydrogen bonding, in conjunction with a weak interaction of Van der Waals interaction and the micropore-filling effect.

\subsection{Comparison with Other Adsorbents}

In order to estimate the efficiency of CAP adsorption onto AC, a comparative assessment with other adsorbents previously described in the literatures is shown in Table 8. CAP adsorption is compared based on Langmuir parameters $Q_{\max }$ and the equilibrium adsorption capacity $Q_{50}$, which is an indicator of the adsorption capacity at low CAP concentrations. The TO-based activated carbon prepared in this study showed more efficient adsorption capacity of CAP compared with most of the reported adsorbents. On the other hand, AC also exhibited better adsorption at low CAP concentration. For instance, the CAP adsorption capacity of AC was $69.5 \mathrm{mg} / \mathrm{g}$ at $50 \mathrm{mg} / \mathrm{L}$ initial CAP concentration, which was almost 1.7 times higher than the ABA-16 $(40.8 \mathrm{mg} / \mathrm{g})$, while the $Q_{\max }$ of ABA-16 $(209.7 \mathrm{mg} / \mathrm{g})$ was almost 1.5 times higher than that of AC $(137.1 \mathrm{mg} / \mathrm{g})$. The CAP adsorption capacity of AC prepared in this study was much larger than other plant-based activated carbon and is comparable to commercial activated carbon (i.e., Calgon F400) and the best CAP sorbents reported. Therefore, Typha orientalis is a promising precursor material for the preparation of activated carbon to remove CAP.

Table 8. CAP adsorption capacities of AC and other sorbents reported in the literature.

\begin{tabular}{cccc}
\hline Sorbent & $Q_{\max }(\mathbf{m g} / \mathbf{g})$ & $\mathbf{Q}_{\mathbf{5 0}}(\mathbf{m g} / \mathbf{g})^{\mathbf{a}}$ & Reference \\
\hline TO-based activated carbon & 137.1 & 69.5 & This work \\
Calgon F400 & 140.3 & 38.4 & This work \\
Bamboo charcoal & 8.1 & - & {$[23]$} \\
Commercial BC-NaOH & $<3^{\mathrm{b}}$ & - & {$[26]$} \\
fBC-2 & 75.3 & - & {$[49]$} \\
MMSNs@MIPs & 41.7 & - & {$[20]$} \\
MMIPs & 17 & - & {$[41]$} \\
MWCNT-10 & 107.9 & - & {$[21]$} \\
ABA-16 (ordered mesoporous carbon) & 209.7 & 40.8 & {$[24]$} \\
\hline
\end{tabular}

Note: ${ }^{a} \mathrm{Q}_{50}$ is the CAP adsorption capacity for a $50-\mathrm{mg} / \mathrm{L}$ CAP initial concentration. ${ }^{\mathrm{b}}$ Estimated from the graphical representation of the results.

\subsection{Adsorption of CAP in Realistic Water Environment}

In batch adsorption experiments, activated carbon prepared from Typha orientalis had an efficient CAP adsorption capacity in distilled water. In order to evaluate its utilization of AC in a realistic water environment, the CAP adsorption performance in groundwater and treated wastewater were also studied. The characterization parameters of different water types and the CAP removal efficiencies are provided in Table 9. Groundwater has a small amount of organic matter and a high total hardness with high ionic strength. The removal efficiency of CAP by AC in groundwater was slightly lower than that in distilled water. As discussed in Section 3.3, the influence of ionic strength on adsorption of CAP 
onto AC was unapparent. At the low concentration of organic matter, the weak competition between dissolved organic matter and CAP molecules resulted in the slight variation of CAP adsorption capacity of AC in groundwater and distilled water. Treated wastewater greatly suppressed the removal of CAP by AC compared to groundwater and distilled water. This suppression might be due to the relatively high concentration of dissolved organic matter (e.g., humic acid, fulvic acid, soluble microbial by-product, and anthropogenic compounds) in wastewater, which reduced the CAP adsorption capacity of AC through adsorption sites competition or pore blockage. Considering the complex composition of dissolved organic matter, the large-sized molecules such as humic acid could poorly diffuse into the pores of AC and block the micro/mesoporous, while the molecules smaller than pore diameter could compete with CAP for adsorption sites. However, the CAP adsorption capacity of AC still reached about $0.219 \mathrm{mmol} / \mathrm{L}(70.6 \mathrm{mg} / \mathrm{L})$ in treated wastewater, showing a good CAP adsorption performance. The results revealed that AC can be successfully used to adsorb CAP in a realistic water environment.

Table 9. Chemical characteristics of water types and removal of CAP.

\begin{tabular}{cccccc}
\hline Water types & $\mathbf{p H}$ & TOC $(\mathbf{m g} / \mathbf{L})$ & $\begin{array}{c}\text { Total Hardness } \\
\mathbf{C a C O}_{3}(\mathbf{m g} / \mathbf{L})\end{array}$ & $\mathbf{Q}(\mathbf{m m o l} / \mathbf{g})$ & Removal Rate (\%) \\
\hline Distilled water & 6.35 & 0 & 0 & 0.278 & 83.4 \\
Groundwater & 7.78 & 2.3 & 320.8 & 0.273 & 80.9 \\
Treated wastewater & 7.72 & 18.9 & 297.5 & 0.219 & 65.6 \\
\hline
\end{tabular}

\section{Conclusions}

In this work, we successfully explored a low-cost activated carbon (AC) prepared from Typha orientalis with phosphoric acid activation for chloramphenicol (CAP) antibiotic removal. AC had a mostly mesoporous structure with a relatively large surface area $\left(794.8 \mathrm{~m}^{2} / \mathrm{g}\right)$. Boehm's titration proved that the acidic functional groups were dominant on the surface of $\mathrm{AC}$, and their content was twice that of the basic functional groups. AC had promising removal efficiency and adsorption performance $(137.1 \mathrm{mg} / \mathrm{g})$ with respect to CAP. The CAP adsorption data well fitted the pseudo-second-order kinetic model and Freundlich isotherm model. Several mechanisms of CAP adsorption onto the AC were elaborated, which include $\pi-\pi$ electron-donor-acceptor (EDA) interaction, hydrophobic interaction, and hydrogen-bonding interaction, in conjunction with the weak interaction of Van der Waals interaction and the micropore-filling effect. In a realistic water environment, AC still exhibited high CAP removal efficiency. Finally, AC prepared from Typha orientalis can be identified as an economical and efficient adsorbent for CAP removal from aqueous solutions.

Acknowledgments: We gratefully acknowledge financial support from the National Natural Science Foundation of China (No. 51720105013), China Major Science and Technology Program for Water Pollution Control and Treatment (No. 2017ZX07101003) and the Independent Innovation Foundation of Shandong University (2014JC023).

Author Contributions: Yiran Li, Hai Liu and Jian Zhang conceived and designed the experiments. Yiran Li performed all the experiments, data analysis, and wrote the manuscript. Extensive editing and revisions to the final manuscript and conclusions were contributed by Yiran Li and Hai Liu. Jian Zhang contributed to the final proof reading.

Conflicts of Interest: The authors declare no conflict of interest.

\section{References}

1. Hanekamp, J.C.; Bast, A. Antibiotics exposure and health risks: Chloramphenicol. Environ. Toxicol. Pharmacol. 2015, 39, 213-220. [CrossRef] [PubMed]

2. Hamidi-Asl, E.; Dardenne, F.; Blust, R.; De Wael, K. An improved electrochemical aptasensor for chloramphenicol detection based on aptamer incorporated gelatine. Sensors 2015, 15, 7605-7618. [CrossRef] [PubMed] 
3. Cunha, B.A. Antibiotic side effects. Med. Clin. N. Am. 2001, 85, 149-185. [CrossRef]

4. Doody, M.M.; Linet, M.S.; Glass, A.G.; Curtis, R.E.; Pottern, L.M.; Rush, B.B.; Boice, J.D., Jr.; Fraumeni, J.F., Jr.; Friedman, G.D. Risks of non-hodgkin's lymphoma, multiple myeloma, and leukemia associated with common medications. Epidemiology 1996, 7, 131-139. [CrossRef] [PubMed]

5. Krasinski, K.; Perkin, R.; Rutledge, J.C. Gray baby syndrome revisited. Clin. Pediatr. 1982, 21, 571-572. [CrossRef] [PubMed]

6. Neu, H.C. The crisis in antibiotic resistance. Science 1992, 257, 1064-1074. [CrossRef] [PubMed]

7. European Commission. Commission decision 2003/181/EC of 13 March 2003. Off. J. Eur. Commun. 2003, $71,17-18$.

8. Zhou, C.; Zhang, X.; Huang, X.; Guo, X.; Cai, Q.; Zhu, S. Rapid detection of chloramphenicol residues in aquatic products using colloidal gold immunochromatographic assay. Sensors 2014, 14, 21872-21888. [CrossRef] [PubMed]

9. Daughton, C.G.; Ternes, T.A. Pharmaceuticals and personal care products in the environment: Agents of subtle change? Environ. Health Perspect. 1999, 107, 907-938. [CrossRef] [PubMed]

10. Liu, H.; Zhang, G.; Liu, C.-Q.; Li, L.; Xiang, M. The occurrence of chloramphenicol and tetracyclines in municipal sewage and the Nanming river, Guiyang city, China. J. Environ. Monit. 2009, 11, 1199-1205. [CrossRef] [PubMed]

11. Xia, S.; Gu, Z.; Zhang, Z.; Zhang, J.; Hermanowicz, S.W. Removal of chloramphenicol from aqueous solution by nanoscale zero-valent iron particles. Chem. Eng. J. 2014, 257, 98-104. [CrossRef]

12. Ahmed, M.B.; Zhou, J.L.; Ngo, H.H.; Guo, W.; Thomaidis, N.S.; Xu, J. Progress in the biological and chemical treatment technologies for emerging contaminant removal from wastewater: A critical review. J. Hazard. Mater. 2017, 323, 274-298. [CrossRef] [PubMed]

13. Czech, B.; Rubinowska, $\mathrm{K}$. $\mathrm{TiO}_{2}$-assisted photocatalytic degradation of diclofenac, metoprolol, estrone and chloramphenicol as endocrine disruptors in water. Adsorption 2013, 19, 619-630. [CrossRef]

14. Csay, T.; Rácz, G.; Takács, E.; Wojnárovits, L. Radiation induced degradation of pharmaceutical residues in water: Chloramphenicol. Radiat. Phys. Chem. 2012, 81, 1489-1494. [CrossRef]

15. Wang, J.; Sun, W.; Xu, C.; Liu, W. Ozone degradation of chloramphenicol: Efficacy, products and toxicity. Int. J. Environ. Technol. Manag. 2012, 15, 180-192. [CrossRef]

16. Xie, F. Research on irradiation-induced degradation products and mechanism of chloramphenicol in animal derived food [MSc thesis]. China BJ Chin. Acad. Agric. Sci. 2008, 16, 34.

17. Zhang, Y.; Shao, Y.; Gao, N.; Gao, Y.; Chu, W.; Li, S.; Wang, Y.; Xu, S. Kinetics and by-products formation of chloramphenicol (CAP) using chlorination and photocatalytic oxidation. Chem. Eng. J. 2018, 333, 85-91. [CrossRef]

18. Liu, H.; Zhang, J.; Ngo, H.H.; Guo, W.; Wu, H.; Guo, Z.; Cheng, C.; Zhang, C. Effect on physical and chemical characteristics of activated carbon on adsorption of trimethoprim: Mechanisms study. RSC Adv. 2015, 5, 85187-85195. [CrossRef]

19. Zhu, Z.; Xie, J.; Zhang, M.; Zhou, Q.; Liu, F. Insight into the adsorption of PPCPs by porous adsorbents: Effect of the properties of adsorbents and adsorbates. Environ. Pollut. 2016, 214, 524-531. [CrossRef] [PubMed]

20. Dai, J.; He, J.; Xie, A.; Gao, L.; Pan, J.; Chen, X.; Zhou, Z.; Wei, X.; Yan, Y. Novel pitaya-inspired well-defined core-shell nanospheres with ultrathin surface imprinted nanofilm from magnetic mesoporous nanosilica for highly efficient chloramphenicol removal. Chem. Eng. J. 2016, 284, 812-822. [CrossRef]

21. Zhao, H.; Liu, X.; Cao, Z.; Zhan, Y.; Shi, X.; Yang, Y.; Zhou, J.; Xu, J. Adsorption behavior and mechanism of chloramphenicols, sulfonamides, and non-antibiotic pharmaceuticals on multi-walled carbon nanotubes. J. Hazard. Mater. 2016, 310, 235-245. [CrossRef] [PubMed]

22. Sun, K.; Shi, Y.; Xu, W.; Potter, N.; Li, Z.; Zhu, J. Modification of clays and zeolites by ionic liquids for the uptake of chloramphenicol from water. Chem. Eng. J. 2017, 313, 336-344. [CrossRef]

23. Liao, P.; Zhan, Z.; Dai, J.; Wu, X.; Zhang, W.; Wang, K.; Yuan, S. Adsorption of tetracycline and chloramphenicol in aqueous solutions by bamboo charcoal: A batch and fixed-bed column study. Chem. Eng. J. 2013, 228, 496-505. [CrossRef]

24. Mohd Din, A.T.; Ahmad, M.A.; Hameed, B.H. Ordered mesoporous carbons originated from non-edible polyethylene glycol 400 (PEG-400) for chloramphenicol antibiotic recovery from liquid phase. Chem. Eng. J. 2015, 260, 730-739. [CrossRef] 
25. Muller, J.; Huaux, F.; Moreau, N.; Misson, P.; Heilier, J.-F.; Delos, M.; Arras, M.; Fonseca, A.; Nagy, J.B.; Lison, D. Respiratory toxicity of multi-wall carbon nanotubes. Toxicol. Appl. Pharm. 2005, 207, 221-231. [CrossRef] [PubMed]

26. Fan, Y.; Wang, B.; Yuan, S.; Wu, X.; Chen, J.; Wang, L. Adsorptive removal of chloramphenicol from wastewater by $\mathrm{NaOH}$ modified bamboo charcoal. Bioresour. Technol. 2010, 101, 7661-7664. [CrossRef] [PubMed]

27. Liu, H.; Liu, W.; Zhang, J.; Zhang, C.; Ren, L.; Li, Y. Removal of cephalexin from aqueous solutions by original and $\mathrm{Cu}(\mathrm{II}) / \mathrm{Fe}(\mathrm{III})$ impregnated activated carbons developed from lotus stalks kinetics and equilibrium studies. J. Hazard. Mater. 2011, 185, 1528-1535. [CrossRef] [PubMed]

28. Shi, Q.; Zhang, J.; Zhang, C.; Li, C.; Zhang, B.; Hu, W.; Xu, J.; Zhao, R. Preparation of activated carbon from cattail and its application for dyes removal. J. Environ. Sci. 2010, 22, 91-97. [CrossRef]

29. Zhang, J.; Shi, Q.; Zhang, C.; Xu, J.; Zhai, B.; Zhang, B. Adsorption of neutral red onto Mn-impregnated activated carbons prepared from Typha orientalis. Bioresour. Technol. 2008, 99, 8974-8980. [CrossRef] [PubMed]

30. Qiang, Z.; Adams, C. Potentiometric determination of acid dissociation constants ( $\mathrm{p} K_{\mathrm{a}}$ ) for human and veterinary antibiotics. Water Res. 2004, 38, 2874-2890. [CrossRef] [PubMed]

31. Dubinin, M.M. The potential theory of adsorption of gases and vapors for adsorbents with energetically nonuniform surfaces. Chem. Rev. 1960, 60, 235-241. [CrossRef]

32. Boehm, H.P. Surface oxides on carbon and their analysis: A critical assessment. Carbon 2002, 40, 145-149. [CrossRef]

33. Noh, J.S.; Schwarz, J.A. Estimation of the point of zero charge of simple oxides by mass titration. J. Colloid Interface Sci. 1989, 130, 157-164. [CrossRef]

34. Eaton, A.; Clesceri, L.; Greenberg, A. Standard Methods for Examination of Water and Wastewater; American Public Health Association, American Water Works Association, Water Environment Federation: Washington, DC, USA, 1998.

35. Thommes, M.; Kaneko, K.; Neimark Alexander, V.; Olivier James, P.; Rodriguez-Reinoso, F.; Rouquerol, J.; Sing Kenneth, S.W. Physisorption of gases, with special reference to the evaluation of surface area and pore size distribution (IUPAC Technical Report). Pure Appl. Chem. 2015, 87, 1051-1069.

36. Gabyshev, V.A.; Gabysheva, O.I. Adsorption of tetracycline and sulfamethoxazole on crop residue-derived ashes: Implication for the relative importance of black carbon to soil sorption. Environ. Sci. Technol. 2011, 45, 5580-5586.

37. Kasaoka, S.; Sakata, Y.; Tanaka, E.; Naitoh, R. Design of molecular-sieve carbon. Studies on the adsorption of various dyes in the liquid phase. Int. Chem. Eng. 1989, 29, 734-742.

38. Xue, C.; Qi, P.; Li, M.; Liu, Y. Characterization and sorptivity of the plesiomonas shigelloides strain and its potential use to remove $\mathrm{Cd}^{2+}$ from wastewater. Water 2016, 8, 241. [CrossRef]

39. Ho, Y.-S.; McKay, G. Pseudo-second order model for sorption processes. Process Biochem. 1999, 34, 451-465. [CrossRef]

40. Qin, L.; Zhou, Z.; Dai, J.; Ma, P.; Zhao, H.; He, J.; Xie, A.; Li, C.; Yan, Y. Novel N-doped hierarchically porous carbons derived from sustainable shrimp shell for high-performance removal of sulfamethazine and chloramphenicol. J. Taiwan Inst. Chem. E 2016, 62, 228-238. [CrossRef]

41. Ma, W.; Dai, J.; Dai, X.; Da, Z.; Yan, Y. Core-shell molecularly imprinted polymers based on magnetic chitosan microspheres for chloramphenicol selective adsorption. Monatshefte Chem. 2015, 146, 465-474. [CrossRef]

42. Langmuir, I. The adsorption of gases on plane surfaces of glass, mica and platinum. J. Am. Chem. Soc. 1918, 40,1361-1403. [CrossRef]

43. Freundlich, H.M.F. Over the adsorption in solution. J. Phys. Chem. 1906, 57, 385-470.

44. Higuchi, T.; Marcus, A.D.; Bias, C.D. The kinetics of degradation of chloramphenicol in solution. II. Over-all disappearance rate from buffered solutions. J. Am. Pharm. Assoc. 1954, 43, 129-134. [CrossRef]

45. Mitchell, S.M.; Ullman, J.L.; Teel, A.L.; Watts, R.J. Hydrolysis of amphenicol and macrolide antibiotics: Chloramphenicol, florfenicol, spiramycin, and tylosin. Chemosphere 2015, 134, 504-511. [CrossRef] [PubMed]

46. Jing, X.-R.; Wang, Y.-Y.; Liu, W.-J.; Wang, Y.-K.; Jiang, H. Enhanced adsorption performance of tetracycline in aqueous solutions by methanol-modified biochar. Chem. Eng. J. 2014, 248, 168-174. [CrossRef]

47. Zhou, J.-H.; Sui, Z.-J.; Zhu, J.; Li, P.; Chen, D.; Dai, Y.-C.; Yuan, W.-K. Characterization of surface oxygen complexes on carbon nanofibers by TPD, XPS and FT-IR. Carbon 2007, 45, 785-796. [CrossRef] 
48. Xiao, F.; Pignatello, J.J. $\pi^{+}-\pi$ interactions between (hetero)aromatic amine cations and the graphitic surfaces of pyrogenic carbonaceous materials. Environ. Sci. Technol. 2015, 49, 906-914. [CrossRef] [PubMed]

49. Ahmed, M.B.; Zhou, J.L.; Ngo, H.H.; Guo, W.; Johir, M.A.H.; Sornalingam, K.; Sahedur Rahman, M. Chloramphenicol interaction with functionalized biochar in water: Sorptive mechanism, molecular imprinting effect and repeatable application. Sci. Total Environ. 2017, 609, 885-895. [CrossRef] [PubMed] 